\title{
Knowledge and Linguistic Creativity Interaction in the Media Discourse
}

\author{
Olga Dmitrievna Vishnyakova ${ }^{1}$, Tatiana Anatolievna Dobroradnykh ${ }^{2}$, Valentina Anatolievna Aleksandrova ${ }^{3} \&$ \\ Maria Victorovna Klimanova ${ }^{4}$ \\ ${ }^{1}$ Lomonosov Moscow State University, Moscow, Russia \\ ${ }^{2}$ Tula State Lev Tolstoy Pedagogical University, Tula, Russia \\ ${ }^{3}$ Belgorod State National Research University, Belgorod, Russia \\ ${ }^{4}$ School with intensive study of English number 1375, Moscow, Russia \\ Correspondence: Olga Dmitrievna Vishnyakova, PhD (Philology), Professor of the Department of English \\ Linguistics, Philological Faculty, Lomonosov Moscow State University, Moscow, Russia. E-mail: \\ ol-vish@mail.ru
}

Received: November 10, 2018

Accepted: December 3, 2018

Online Published: February 24, 2019

doi:10.5539/ijel.v9n2p65

URL: https://doi.org/10.5539/ijel.v9n2p65

\begin{abstract}
The problem of linguistic knowledge and knowledge of the world correlation as applied to linguistic creativity is closely connected with the creative potential of language. Linguistic creativity manifests itself at various levels of linguistic expression and finds its representation in the sphere of meaning transformations. Linguistic meaning can also be regarded as a cultural information container and knowledge of the world carrier, which is particularly important in terms of linguistic and conceptual meaning correlation, which concerns with understanding and interpretation, as well as the process of world view formation.

Linguistic creativity can be regarded primarily as the activity of creating new meaning in order to produce a certain stylistic or rhetorical effect to achieve communicative pragmatic purpose in the course of information transfer.

The Mass Media discourse presented by the written media texts is characterized by the process of interrelation of the informative function of language with the functions of impact and persuasion, and deals with purposeful cognitive activities that include attitudes, motives, evaluations, etc. It is considered to be the area of the target audience political and ideological preferences manipulation, that comprises various linguistic phenomena, characterized by the ability to express evaluative and persuasive meanings. Sobriquet nominations used in the Media discourse play an important role in the process of evaluation and world view formation, as it reflects the peculiar characteristics of the object of nomination, significant for the linguocultural community in question in a certain period of time.
\end{abstract}

Keywords: linguistic creativity, linguistic knowledge, knowledge of the world, the Mass Media discourse, sobriquet nomination

\section{Introduction}

\subsection{Knowledge and Linguistic Creativity}

The phenomenon of linguistic creativity within the sphere of the Media finds its representation both in the Internet sources and printed materials as the most important means to produce a certain stylistic and rhetorical effect. Linguistic creativity is a complex process that includes various linguistic means potential realization in order to achieve the basic pragmatic communicative purpose of the speaker (or writer) that concerns special influence to be made on the addressee. The problem under consideration is closely connected with the process of knowledge transfer, with special attention to the knowledge of the world and the linguistic knowledge issues. Due to the fact that knowledge presents itself as combination of information, experience and intuition (Surbhi, 2016) being transformed into the cognitive formats in the human mind, it is passed to further generations or used to create new knowledge on the basis of inferences and manifests itself in different other functions. It should be emphasized in this connection that knowledge possesses the ability of verbal representation at various levels of 
linguistic expression. Thus, language is used as the means of knowledge representation and may to some extent influence knowledge transformation due to its dynamic characteristics.

\subsection{Language as the Source for Linguistic Creativity}

Linguistic creativity, based on the human linguistic competence, realized as the unity of linguistic knowledge and skills, concerns with the creative potential of language and interpretation ability as the indispensable quality of the human mind. It should be noted from the very outset that while discussing the phenomenon in question one has to take into consideration both the process of formation of meaning as well as transformations at the level of linguistic expression. Language serves as the tool of interpretation, which implies realization of the most important linguistic and extralinguistic characteristics of the units of language that enable the possibility for them to be used creatively in certain contexts that represent certain types of discourse. It should be added in this connection that the process of creation in linguistics as well as interpretation and understanding, are considered to be the purposeful cognitive activities that include attitudes, motives, ideological preferences of communicants, with the special reference to the fact of their background knowledge possessions. Otherwise stated, the problem in question should be investigated in detail both in terms of linguistic meanings and ways of linguistic expression transformations as well as taking into consideration the conceptual basis of these processes, i.e. in terms of the role they play in the course of individuals' world view formation, which is of particular concern with the sphere of the Media, where emotional and evaluative components are closely connected with the process of information transfer and find special representation at the level of language.

\section{Material Studied}

The material chosen for the investigation has been borrowed from the Mass Media discourse presented by the written media texts, that comprise interactive linguistic and media components, which present the reliable source for the analysis of linguistic creativity, based on the unity and integration of linguistic knowledge and knowledge of the world. At the same time, one should always bear in mind the fact that the Media discourse is well-known for the increasingly blurred boundaries between written and oral forms of presentation, which manifests itself in its interactive dynamic character.

As in the discursive variety in question the informative function of language is accompanied and supported by the functions of impact and persuasion, the material used comprises contexts that can be analyzed in terms of the linguistic creativity phenomenon manifestation. We have considered the Internet publications of different genres, paying special attention to those samples that contain linguistic creativity representations that refer to various manipulations at the level of meaning and evaluation referred to the area of sobriquet nominations functioning.

Proceeding from the definition of linguistic creativity that implies the idea of transfer and reformation in the sphere of meaning and form in order to produce a certain stylistic or rhetorical effect, we have subjected to the analysis the area of sobriquet nominations, based on the process of creating new meaning or meaning transfer in order to present its evaluative characteristics, taking into consideration the communicative pragmatic aspect of the Media discursive peculiarities. It should also be borne in mind that the authors who created the nicknames under analysis are in most cases anonymous and most of the nominations are used by the writers as sometimes taken from the informational space of somewhat indefinite character, that is from some others' materials or just rumour.

Thus, much attention has been paid to various kinds of materials, including analytical articles, features, comment, news and advertising, that contain political leaders' nicknames, which reflect some new trends in evaluation their activity and personal characteristics, especially when concerned dramatic changes in the governmental structures and political events such as election campaigns or making important decisions concerning domestic and international politics (for instance, texts like The Billary Road to Republican Victory; Donald Trump's new nickname for Hillary Clinton puzzles Germans, etc.).

Most of the examples under consideration refer to the use of linguistic creativity manipulations in the sphere of sobriquet nominations based on the ability of a linguistic meaning to represent various evaluative characteristics in order to achieve a certain stylistic or rhetorical effect to create a specific image of the object of nomination in the consciousness of the addressee via influencing his or her world view and individual evaluation scale. In some situations, context becomes of crucial importance in this connection.

As for the topical attribution of the contexts chosen we have concentrated on the political subjects, presented in the material under discussion, which seems to be of great interest from the point of view of evaluation and persuasion. We have also tried to take into account various geographical areas of presentation as far as the English discourse is concerned. For example, samples from the Australian and American media language were 
subject to the analysis (What nicknames does Bob Hawke go by? Bob, the Silver Bodgie, the Right Honourable the Prime Minister, R. J. Hawke; Brown Sugar-It's Not So Sweet, etc.).

As for the genres and types of the media texts, most of them were taken from the news or analytical sources, though there are comments as well, especially when dealing with the nicknames characteristics used in the already existed materials description. This is due to the fact that some of them need special attention to be paid in terms of the formats of previous knowledge they are based on and the ways of newly created knowledge presentation. Thus, the material under consideration includes both the Media texts and lexicographic and encyclopedic sources to be attracted in the course of a new linguistic meaning formation aimed to achieve a definite communicative pragmatic goal investigation.

\section{Area Descriptions}

\subsection{The State of the Art. Noam Chomsky's Approach to Linguistic Creativity}

We proceed from the premise that though the problem of linguistic creativity has been discussed time and again by linguistic authorities it has not received so far all the attention it deserves. N. Chomsky was one of the first authors, who concentrated his attention on the subject of linguistic creativity in concern with ordinary language use productivity (Chomsky, 1967, p. 4). First and foremost, he takes grammar into consideration and appeals to the issue of the linguistic competence as the most important peculiarity of a human being, paying special attention to the grammatical aspect of the linguistic activity of man, based on some innate grammatical abilities (Chomsky, 1972, p. 89). In other words, in the more usual sense "he detects creativity in ordinary linguistic phenomena" (D'Agostino, 1983, p. 86), though at the same time "Chomsky does distinguish [...] true human creativity from the creativity that may be manifested in everyday linguistic behaviour" (Op. cit., p. 85). According to the outstanding linguist's thesis, "true creativity in a higher sense [...] implies value as well as novelty" (Chomsky, 1966, p. 27). As F. d' Agostino states in his detailed analytical presentation, true creativity presupposes novelty involvement, context appropriateness as well as unpredictability as far as external stimuli are concerned (D'Agostino, 1983, p. 88).

Strictly speaking, every user of the language can be considered to be creative, at least when he or she uses any linguistic expression based on the process of a certain discourse actualization for the first time. Nevertheless, the pivotal point of our investigation concerns functioning of an utterance or a linguistic unit within it, based on the new ways or modes of its realization, for the sake of a certain stylistic or rhetorical effect achievement, due to the communicative pragmatic purpose of the speaker (or writer).

\subsection{Linguistic Creativity in Terms of Cognitive Approach}

One more very important point should be made in this connection that concerns the problem of interrelation between linguistic creativity and human cognitive abilities in terms of the creative abilities and, according to $\mathrm{N}$. Chomsky, limitations that appear as part of this process. He writes that "cognitive systems too set limits on human intellectual development, by virtue of the very structure which makes it possible to acquire rich and comprehensive systems of belief and knowledge" (Chomsky, 1976, p. 123). Thus, the idea of creativity is inseparable from the thesis, according to which the range of human activities is limitable in terms of some innate processes. At the same time creativity as a cognitive process is closely connected with knowledge, based on experiential or individual values, perceptions, etc. and presented at the level of concepts, that is not subject to similar reproduction and can be regarded as the category that refers to the illimitable continuum of cognition and interpretation, including the associative sphere of the mind (Hampton \& Moss, 2003; Jackendoff, 1995; Jary \& Jary, 1991, p. 325). These theoretical issues can be supported by the thesis that creativity manifests itself as "the open-ended ability of all human beings to create and innovate in various ways and for various motivations" (Zawada, 2006). At the same time linguistic restrictions that refer to idiomaticity of language and the linguistic norm and digressions criteria, including discursive characteristics, are supposed to be taken into consideration and the problem of the unlimited ability of language to serve as the source for linguistic creativity implementation still needs to be discussed in detail.

\subsection{Linguistic Meaning as a Cultural Knowledge Container}

As has been mentioned above, the primary goal of our investigation concerns the analysis of the linguistic phenomena potential use for the sake of linguistic creativity, which manifests itself at different levels of language functioning presented in the linguistic knowledge structure. At the same time, it should always be borne in mind that in the course of creative transformations in the domain of language the notion of linguistic meaning is of particular importance. As has been shown in a number of scientific disquisitions, linguistic meaning is an abstract notion that finds its representation in context in the actual speech reality and correlates 
with certain conceptual structures (Kintsch, 1974; Lyons, 1978; Pustejovsky \& Boguraev, (Eds.), 1996; Searle, 1983; Ullmann, 1962). Linguistic meaning manifests itself at various levels of linguistic expression and is characterized by interrelation and interdependence of these levels actualization properties.

One of the most significant properties of linguistic meaning is its ability to serve as a cultural information container and knowledge of the world carrier (Wiezbicka, 1972). Thus, linguistic meaning can be regarded both the objective reflection of the world presented at the level of language, and the means used to shape the world in our mind due to its cognitive peculiarities. Modern linguists pay special attention to the fact that linguistic meaning, being flexible and dynamic, possesses multiple perspectivization (Geeraerts, 2006, pp. 3-4), based on the correlation of its concrete linguistic representations with its abstract nature. For example, Dirk Geeraerts proceeds from the premise that language is a constantly changing structure connected with the process of changing in the outside world, which can be observed in the domain of linguistic meaning changing. The author writes: "Meanings change, and there is a good reason for that: meaning has to do with shaping of our world, but we have to deal with a changing world. New experiences and changes in our environment require that we adapt our semantic categories to transformations of the circumstances, and that we leave room for nuances and slightly deviant cases. For a theory of language, that means that we cannot just think of language as a more or less rigid and stable structure [...] If meaning is the hallmark of linguistic structure, then we should think of those structures as flexible" (Op. cit., p. 4). Thus, taking this statement into consideration we may come to the conclusion that it also corresponds to the phenomenon of linguistic creativity, which is obviously based on the abilities of linguistic meaning to reflect the world and manifest itself as the linguistic core in the process of knowledge of the world structuring.

The problem of meaning in linguistics is presented in the extensive literature on the subject and deals with the whole complex of its characteristics and functions. While speaking of linguistic creativity it should be noted that the process under consideration finds its representation at various levels of linguistic expression and concerns transformations in the domains of both lexical and grammatical meaning as well as new meaning or connotative meaning occurrence as regarded to the linguistic units in question. One of the most vivid characteristics of the process under analysis in terms of linguistic creativity is contextual meaning representation that depends on various contextual factors, which include linguistic and extralinguistic properties of context that determine particular modes of the meaning expression (Martin \& Nakayama, 2000). It should be mentioned in this connection that in accordance with semantic and formal transformations within a linguistic unit in context the process of evaluative connotative meaning appearance deserves special attention within these lines that concerns functioning of sobriquet nominations and their meaning transformations (Ashley, 1989; Gardiner, 1954).

To clarify the point, all these potential qualities of linguistic units mentioned can be described in terms of meaning used as the source of transformations and new meanings appearance for the purpose of stylistic or rhetorical effect creation that refers to the linguistic creativity issue. To reiterate, the following definition of linguistic creativity can be adduced: "Linguistic creativity is primarily the activity of making new meaning by a speaker (in the broadest sense of the user of language in all forms and in all mediums), and the re-creation and re-interpretation of meaning(s) by a receiver" (Zawada, 2006).

\subsection{Linguistic Knowledge and Knowledge of the World Notions}

The phenomenon of linguistic creativity, which is the subject of our research, analyzed in terms of discursive identification, belongs not only to the Mass Media discourse, but also to the discourse of fiction, where the creative potential of language is used extensively as it serves the dominant function of artistic writing to be implemented. At the same time the notion of linguistic creativity is valid in case of scientific, professional, institutional discourses analyses (van Dijk, 2014). This doesn't mean to say that linguistic creativity is presented in all these discursive varieties in the equal terms, though in most of them, being realized as the discourse level category, it plays an important role in speech construction not only as the function of impact fulfillment instrument, but also as the means that takes part in the process of world view formation, including multilingual and multicultural communities. For example, in the area of advertising in South Africa multilingual approach to linguistic creativity in the discursive variety of advertising is applied, which "has given rise to the creation of a new social identity and linguistic creativity seldom seen before" (Ngwenya, 2011). In other words, the process of interaction of linguistic knowledge with knowledge of the world is described in the above example as the basis of new linguocultural issues occurrence. Otherwise stated, the problems mentioned can be referred to the linguistic universals approach based on certain concepts representation that comprise both linguistic knowledge and knowledge of the world formats, encoded by means of linguistic expressions (Wiezbicka, 1972; Cristofaro, 2010). 


\subsection{Linguistic Creativity in Terms of Linguistic Knowledge and Cultural Knowledge Interaction}

We proceed from the premise that correlation between linguistic knowledge and knowledge of the world, also presented as "cultural knowledge", is of particular importance for understanding discursive peculiarities of linguistic creativity manifestations, with special attention to its extralinguistic components. As R. M. Keesing declares, "the boundary between a speaker's knowledge of a language and his/her knowledge of the world poses deep and still unresolved analytical problems" (Keesing, 1979, p. 14). The author states that the term "culture" should be used in a cognitive sense, i.e., in the meaning of a system of knowledge, "a composite of the cognitive systems more or less shared by members of a society" but not only as a way of life or a system of behavior. As for linguistic knowledge, it is understood as part of the same epistemological plane as cultural knowledge. The author writes: "My questions about the language/culture boundary are thus questions about the compartmentalization of one subsystem of knowledge, linguistic knowledge, from other subsystems" (Op. cit., p. 15). T. van Dijk also states that the borderline between the knowledge of language and knowledge of the world is rather vague, which is especially clear in case of lexical knowledge, as meanings of words can be mixed with our conceptual knowledge of the world characteristics. The author pays special attention to the role of knowledge in discourse and the close interaction between the two issues: "Most of our knowledge is acquired by discourse, and our ability to produce and understand discourse is impossible without the activation of massive amounts of knowledge of the world" (van Dijk, 2014, p. 1).

Linguistic knowledge as the linguistic and cognitive notion finds a two-fold explication within the framework of contemporary linguistic studies. To clarify the point, it can be understood in terms of the linguistic competence issue, as realized at the level of practical application, that concerns the use of language in communication ("knowledge of a language"). At the same time most scholars agree that the term "linguistic knowledge" should be applied to the concept of theoretical knowledge, i.e. the knowledge of linguistic regularities and theoretical basis of language ("knowledge about language") (Hughes, 1990, p. 128; Laird, 1966, p. 32; Thornbury, 2007, p. 11).

The latter seems to be more widely spread among specialists and as referred to communication it is also connected with the notion of background knowledge that concerns cultural knowledge that people share within a certain linguocultural community (Wiezbicka, 1972). As for the linguistic creativity issue within this context it should be mentioned that understanding to be achieved as the result of communication process, which is based on adequate interpretation of linguistic meanings in question concerning creative attitude to language and background knowledge realization.

\section{Methods and Techniques}

In the course of the investigation the following methods have been used as the methodological basis of the research due to its main purpose that deals with the role of knowledge and the linguistic creativity phenomenon in terms of a certain stylistic and rhetorical effect production in the Media discourse. It should be emphasized that the basic methodological foundation of the research is of complex nature as it comprises such issues as lexicographic analysis (that concerns with definitions excerpted from dictionaries), linguostylistic analysis (that deals with the linguistic units intrinsic stylistic potential), functional-stylistic analysis (that concerns the linguistic units abilities to be used as stylistic connotations carriers within certain varieties of speech), intralinguistic semantic analysis (based on the process of certain characteristics of meaning manifestation as far as the linguistic units under consideration are concerned), contextual analysis (dealing with the role of contexts in which the phenomena in question find their representation), linguoculturological analysis (which concerns with the ability of a linguistic unit to serve as a carrier of culturally significant meaning), discursive analysis (that comprises both linguistic and extralinguistic peculiarities of a linguistic unit functioning in actual speech, including the notions of linguistic knowledge and knowledge of the world).

As for sobriquet nominations properties, some additional aspects of the investigation should be taken into account that require functional semantic analysis and linguosemiotic, accompanied by general semiotic, analyses to be included into the scope of the research, due to the fact that functional semantic analysis deals with the subject-matter and evaluative characteristics of linguistic units representation, while various types of semiotic analyses, including the linguosemiotic one, concern the semiotic status of nicknames within the system of language as well as their nominative and evaluative functions representation as applied to the extralinguistic semiotic reality. 


\section{Results and Discussion}

\subsection{Sobriquet Nomination and Evaluation Process}

As has been mentioned above, in the discourse of Media the most important speech functions, such as functions of communication, information and impact, including persuasion, find their representation and close interaction. It should be noted from the very outset that they all depend on the basic functions of language that include such significant areas as nominative, cognitive, communicative pragmatic and evaluative.

As an integrative sphere of human activity the Media discourse encompasses an essential scope of topics and ways of their presentation on the basis of various linguistic phenomena actualization, including linguistic creativity. The interpretative potential of language enables people to use this approach in order to express emotional and evaluative attitudes to the subjects and situations of their description at the level of verbal nomination. One of the most popular ways of presentation is the use of nicknames (sobriquet nominations), which has become extremely extensive and acceptable at all levels of communication. Proceeding from the definition, which says that "a nickname is a familiar or humorous, sometimes derogatory, name given to a specific person, place, or thing instead of or as well as the proper name. It commonly reflects some key aspect of an individual's physical appearance, personality, or achievement" (Delahunty, 2004), -we pass on to the actual material, where linguistic creativity as the way of humorous or ironical presentation helps to demonstrate the manipulative potential of the language of the Media, based on the interrelation of cultural and linguistic knowledge issues. For example, one of the popular political leaders in Australia - Bob Hawke is known for his nickname Ol' Silver: "Bob Hawke goes by Ol' Silver"; "Ol' Silver" as Paul Keating referred to him is a legend! Streets ahead of today's poll driven spin doctoring short sighted election driven jokers!" (URL: http://www.answers.com/Q/What_nicknames_does_Bob_Hawke_go_by) due to his silver hair, i.e. linguistically based on the metonymic way of representation. At the same time people of Australia can present one more nomination used for Bob Hawke, which corresponds to the previous one, but requires specific background knowledge possession to be encoded and understood - The Silver Bodgie: "Bob Hawke: characteristically quick out of the blocks, the Silver Bodgie has been doing the rounds since early in the campaign [...]" (URL: http://buggery.org/tag/bob-hawke/); "When drafting a dessert for Bob Hawke, Kitchen Cabinet recipe guru Wendy Sharpe and I had many factors to consider. He doesn't have a super-sweet tooth, for starters. Plus it had to be transportable. And - I'm not going to lie to you - we were hoping to pay tribute in some way to the famous Hawke coif. So the Silver Bodgie Choux Buns were born" (URL: https://www.bellsatkillcare.com.au/article/an-afternoon-with-annabel). The use of this nickname including the notion of "bodgie" is associated with his appearance and energy, though at the same time presupposes a certain kind of shared background knowledge on the part of the addressee, that should reflect some facts of biography and political activity of the person in question. Thus, the following information may attract attention of the Media audience in order to excerpt the evaluative key message from the context, based on certain cultural and linguistic realia: "Bodgies and Widgies refer to a youth subculture that existed in Australia and New Zealand in the 1950s, similar to the rocker culture in the UK or Greaser culture in the United States. Most Bodgies rode motorbikes but some had cars a lot of the ones with cars had hotted up cars e.g. mag wheels hot dog muffler etc.

The males were called Bodgies and the females were called Widgies. Bodgies were often depicted in Australian media and folk-lore as louts. On 1 February 1951 the Sydney Morning Herald wrote on its front page: "What with "bodgies" growing their hair long and getting around in satin shirts, and "wedgies" cutting their hair short and wearing jeans, confusion seems to be arising about the sex of some Australian adolescent [...]. Former Prime Minister of Australia Bob Hawke was nicknamed the Silver Bodgie by the Australian media for his thick silver-grey hair worn in the bodgie style and loutish behaviour before entering politics" (URL: https://en.wikipedia.org/wiki/Bodgies_and_Widgies).

\subsection{Ways of Metaphorical Presentation in Sobriquet Nomination}

It is a well-established fact that in the USA, for example, within the area of politics the tradition of nicknames creation has become regular and completely acceptable. This has found its reflection in the Internet and printed materials (URL: https://en.wikipedia.org/wiki/List_of_nicknames_of_United_States_Presidents\#cite_note-66), let alone the whole collections of nicknames that appear in the course of election campaigns (URL: http://www.cbsnews.com/news/donald-trumps-new-nickname-for-hillary-clinton-puzzles-germans/; URL: http://www.breitbart.com/2016-presidential-race/2016/07/25/trump-coins-new-nickname-hillary-rotten-clin ton/). In other words, linguistic creativity in politics finds its representation as the actual mode of communication, realized in the Media discourse, based on linguistic and knowledge of the world manifestations.

No less important is the situation with sobriquet nominations created on the basis of metaphorical representation 
of colors that refers to ethnical or national properties. Thus, in the sphere of political Media discourse one comes across linguistic units, which may possess various types of evaluation, i.e. from strongly negative to exceedingly positive. This problem is obviously concerned with the political correctness issues. For instance, in the following contexts the name of a well-known political figure of the USA Condoleezza Rice is mentioned both in the negative and positive evaluative contexts: "The now-deceased Libyan leader harbored a bizarre crush on the former Secretary of State, assembling an adoring scrapbook featuring news photos of her and at one point writing a song called "Black Flower in the White House" (URL: http://jezebel.com/5852714/what-can-we-learn-from-condoleezza-rice); "I must admit that I do enjoy the barbed satire of Garry Trudeau's Doonesbury. Recently, Trudeau's political observations ran a red light in referring to the nation's National Security Advisor, Dr. Condoleezza Rice, a black woman, as "brown sugar". Frankly, the political satire in the April 7, 2004 Doonesbury escapes me and most women I know, black or white, liberal or conservative, Democrat or Republican" (URL: http://images.ucomics.com/comics/db/2004/db040407.gif); "Bush's nicknaming proclivity is noted enough to have attracted a variety of satire, including a New York Times humor piece and a Doonesbury strip where "Condi" is admonished with the phrase "Careful, Brown Sugar" (Op. cit.). As has been mentioned before, the metaphorical transformation of meaning is referred to its use in a special context. For instance, in the first example adduced above it is obviously concerned with the creative use of the parallel construction (lexical and syntactic parallelism) that contains the opposition of two colors, on the one hand, and two idiomatic collocations, one of them is a proper name ("the black flower" and "the White House"), which is able to produce a certain stylistic effect, based on the positive evaluative connotations, whereas in the second example adduced the concept of "the black sugar" needs special reference to such notions as "unrefined or partially refined sugar" (The American Heritage Desk Dictionary, 1981), as well as certain background knowledge possession that goes back to the "Rolling Stones" popular song named "Brown Sugar", associated with the slang nomination of the prohibited narcotics (URL: http://iwf.org/news/2434619/Brown-Sugar-It's-Not-So-Sweet).

The next example that contains sobriquet nominations of the former political authorities and taken from the discourse of Media demonstrates the linguistic creativity abilities in terms of the linguistic knowledge actualization that concerns the word-building and composition potential of language. Thus, for instance, the nickname of collective character based on the two proper names unity (Bill and Hillary Clinton) is presented in the following cases: "In the Democrats' case, the full-throttle emergence of Billary, the joint Clinton candidacy, is measured mainly within the narrow confines of the short-term horse race" (URL: https://www.nytimes.com/2008/01/27/opinion/27rich.html); "Billary wants nothing more than to be president, and she will run against Obama, because this is her last chance. Public sentiment now realizes she was the best candidate of the Democrats, and the best candidate for the 2008 Election" (URL: http://www.dailymail.co.uk/news/article-1045090/Obama-President-Dont-count-chickens.html). “Now she's claiming disingenuously that if John Edwards had been exposed as an adulterer earlier in the campaign, his votes would have gone to her and she would now be the candidate. While Billary will ostensibly support Obama" (Op. cit.); "Obama also called for better data on a range of issues around criminal justice. [...] BLM is nothing more than a political action group. Reply. Pick. [...] strategy for BLM operatives' next audience that will be graciously conceded to them by (URL: https://www.theguardian.com/us-news/2015/oct/22/obama-black-lives-matter-movement-policing).

As has been stated above, the phenomenon of linguistic creativity used in order to produce a certain stylistic or rhetorical effect may be referred to the process of world view formation and the ways of reflection the knowledge of the world issues. The following example can be described as the one that correlates with political preferences chosen according to the state of affairs contemporary to the moment of speaking, where the author lays special emphasis on the order of the names included into the collective nickname presentation: "Billary was used while Bill was president. Since Hillary is now in the forefront, I suggest we use "Hillbilly" now. [...] There is no such thing as man-made climate change. The myth is nothing more than a scheme to gain control and money" (URL: http://ecowatch.com/2015/05/05/climate-deniers-run-for-president/). Otherwise stated, as the dominant role of Hillary Clinton at that moment was obvious, the structure of the collective nickname was changed thus signaling about transformations in its meaning and cultural significance.

\section{Conclusion}

Thus, we have adduced some of the most vivid examples of linguistic creativity actualization in the sphere of sobriquet nominations that demonstrate the process of interrelation of linguistic knowledge with knowledge of the world. Most of them are used to produce a certain stylistic and rhetorical effect and within the scope of the Media discourse are supposed to fulfill the function of manipulating the target audience so that to implement the 
function of persuasion and sometimes stylistic impact. It should be noted in this connection that though the sphere of sobriquet nominations is not the only one to present the vivid examples of transformations of meaning and form in accordance with the linguistic creativity process actualization, the material under consideration demonstrates that the Media discourse can be subject to the analysis in terms of the interactive communicative issues, based on the purpose of the pragmatic communicative function realization, with special consideration to the evaluative and persuasive potential of linguistic units.

As has been shown above, the material excerpted from the political sphere of the Media discourse deals with the political leaders' personal characteristics reflected in their nicknames, based on the process of linguistic creativity and aimed at the expression of a certain attitude to the personality in question, presented in the articles of various types, including news, analysis, features, comment and advertising. Some of the sobriquet nominations under analysis have been formed to produce a certain positive influence on the target audience to support the meliorative characteristics of the image of a certain leader, like for example, in cases with "Silver Bodgie" (Bob Hawke), though a bit ironical, and "Black Flower in the White House" (Condoleezza Rice), elegant and romantic, in which the cognitive abilities of the addressee are being activated and accompanied by attracting attention and stimulating positive associations and emotions, according to the meanings of the linguistic units that represent the notions in question.

At the same time, as has already been mentioned, the evaluative component of such nomination as "Hillbilly" is first and foremost closely connected with the background knowledge level of the addressee, which implies knowledge about the political situation in the country and the choice of priorities trends in the government circles as well as some important facts concerning Mr Clinton's activity while being President. It should be noted within these lines that as far as sobriquet nominations meaning interpretations are concerned much depends on the context of their functioning, for example, juxtaposition with such phrases as "There is no such thing as man-made climate change", "The myth is nothing more than a scheme to gain control and money", that can clearly demonstrate the attitude of the author to the problems discussed and be analyzed in terms of communicative pragmatic aspects of language concerned with the use of linguistic creativity potential.

A similar situation may be referred to the "Brown Sugar" case, which presents Condoleezza Rice's activity in terms of its pejorative characteristics and may be originated to the collocation slang meaning presented, for instance, in the "Rolling Stones" hit, which of course seeks the addressee's background knowledge issues, as well as its functioning in the adduced above context example of "Careful, Brown Sugar". Otherwise stated, within a certain context the meaning of the sobriquet nomination may as well acquire some new expressive and evaluative characteristics used to produce a special impact on the addressee, in which the function of persuasion in the course of communication is being manifested.

In conclusion, it should be mentioned that linguistic creativity based on certain knowledge issues, closely connected with it, may be used extensively in the political sphere of the Media, especially in situations that reflect expressive, emotional and evaluative attitudes and characteristics of certain objects and phenomena, including political personalities, in order to produce a certain stylistic or rhetorical effect and achieve the required communicative pragmatic purposes.

\section{References}

Ashley, L. R. N. (1989). What's in a name? Everything you wanted to know. Baltimore: Genealogical Publishing Co.

Bob Hawke. Retrieved from http://buggery.org/tag/bob-hawke/

Bodgies_and_Widgies. Retrieved from https://en.wikipedia.org/wiki/Bodgies_and_Widgies

Brown Sugar - It's Not So Sweet. Retrieved from http://iwf.org/news/2434619/Brown-Sugar---It's-Not-So-Sweet

Chomsky, N. (1966). Cartesian Linguistics (Studies in Language). N.Y.: Harper \& Row.

Chomsky, N. (1967). Recent Contributions to the Theory of Innate Ideas. Synthese, 17, 2-11. https://doi.org/10.1007/BF00485013

Chomsky, N. (1972). Language and Mind. N.Y.: Harcourt Brace Jovanovich.

Cristofaro, S. (2010). Language Universals and Linguistic Knowledge. In J. S. Jae (Ed.), The Oxford Handbook of Linguistic Typology (Print publication date: Nov. 2010, Online publication date: Sep. 2012). https://doi.org/10.1093/oxfordhb/9780199281251.013.0013

D’Agostino, F. (1983). Chomsky on creativity. Synthese, 58, 85-117. https://doi.org/10.1007/BF00485363 
Delahunty, A. (2004). Goldenballs and the Iron Lady: A Little Book of Nicknames. Oxford University Press.

Donald Trump's new nickname for Hillary Clinton puzzles Germans. Retrieved from http://www.cbsnews.com/news/donald-trumps-new-nickname-for-hillary-clinton-puzzles-germans/

Doonesbury Comic Strip. Retrieved from http://images.ucomics.com/comics/db/2004/db040407.gif

Gardiner, A. (1954). The Theory of Proper Names. A Controversal Essay. Oxford: Oxford University Press.

Geeraerts, D. (2006). Introduction. A rough guide to cognitive linguistics. In D. Geeraerts (Ed.), Cognitive Linguistics: Basic Readings (pp. 1-28). Berlin: Mouton de Gruyter. https://doi.org/10.1515/9783110199901

Hampton, J., \& Moss, H. (2003). Concepts and meaning: Introduction to the special issue on conceptual representation. Language and Cognitive Processes, 18(5/6), 505-512. https://doi.org/10.1080/01690960344000161

Houghton Mifflin Company. (1981). The American Heritage Desk Dictionary. Boston: Houghton Mifflin.

Hughes, M. (1990). The Learning and Teaching of a Lesser Used Language for Communication. Proceedings of the Symposium on The Teaching of Foreign Languages in European Universities, Florence, pp. 14-16.

Jackendoff, R. (1995). Semantics and Cognition. Cambridge, Mass.: The MIT Press.

Jary, D., \& Jary, J. (1991). Collins dictionary of sociology. Glasgow: Harper Collins.

Keesing, R. M. (1979). Linguistic Knowledge and Cultural Knowledge: Some Doubts and Speculations. American Anthropologist, 14-36. https://doi.org/10.1525/aa.1979.81.1.02a00020

Kintsch, W. (1974). The representation of meaning in memory. N.Y.; Toronto.

Laird, C. (1966). The Miracle of Language. A Fawcett Premier Book.

List of nicknames of United States Presidents. Retrieved from https://en.wikipedia.org/wiki/List_of_nicknames_of_United_States_Presidents\#cite_note-66

Lyons, J. (1978). Semantics. London etc.: Cambridge University Press.

Martin, J. N., \& Nakayama, T. K. (2000). Intercultural Communication in Contexts. California: Mayfield Publishing Company.

Meet 3 More Climate Deniers Who Want to Be Your President. Retrieved from http://ecowatch.com/2015/05/05/climate-deniers-run-for-president/

Ngwenya, T. (2011). Social identity and linguistic creativity: Manifestations of the use of multilingualism in South African advertising. Southern African Linguistics and Applied Language Studies, 29(1), 1-16. https://doi.org/10.2989/16073614.2011.583082

Obama for President? Don't count your chickens. Retrieved from http://www.dailymail.co.uk/news/article-1045090/Obama-President-Dont-count-chickens.html

Obama praises black lives matter movement. Retrieved from https://www.theguardian.com/us-news/2015/oct/22/obama-black-lives-matter-movement-policing

Pustejovsky, J., \& Boguraev, B. (1996). Lexical Semantics: The problem of polysemy. Oxford: Clarendon Press.

Searle, J. (1983). Expression and Meaning. London: Cambridge University Press.

Secrets From "Black Flower" Robot-Saint Condoleezza Rice. Condi was grateful that Muammar Gaddafi's $\begin{array}{lllll}\text { fixation on her wasn't from } & \end{array}$ $\mathrm{http} / / /$ jezebel.com/5852714/what-can-we-learn-from-condoleezza-rice

Surbhi, S. (2016). Difference Between Information and Knowledge. Retrieved from $\mathrm{http} / /$ keydifferences.com/difference-between-information-and-knowledge.html

The Billary Road to Republican Victory: Frank Rick NY Times. By Frank Rich. Jan. 27, 2008. Retrieved from https://www.nytimes.com/2008/01/27/opinion/27rich.html

Thornbury, S. (2007). How to Teach Speaking. Pearson Education Limited.

Trump Coins New Nickname: Hillary 'Rotten' Clinton. Retrieved from http://www.breitbart.com/2016-presidential-race/2016/07/25/trump-coins-new-nickname-hillary-rotten-clint on/

Ullmann, S. (1962). Semantics. An Introduction to the Science of Meaning. Oxford: Blackwell. 
Van Dijk, T. A. (2014). Discourse and Knowledge: A Sociocognitive Approach. Cambridge University Press. https://doi.org/10.1017/CBO9781107775404

What a Fabulous Afternoon tea it was. An Afternoon with Annabel. October 22, 2017. Retrieved from https://www.bellsatkillcare.com.au/article/an-afternoon-with-annabel

What nicknames does Bob Hawke go by? Retrieved fromn http://www.answers.com/Q/What_nicknames_does_Bob_Hawke_go_by

Wiezbicka, A. (1972). Semantic Primitives. Frankfurt: Athenaum Verlag.

Zawada, B. (2006). Linguistic creativity from a cognitive perspective. Journal Southern African Linguistics and $\begin{array}{lllll}\text { Applied Language } & \text { Studies, } & \text { 24). } & \text { Retrieved }\end{array}$ https://www.tandfonline.com/doi/pdf/10.2989/16073610609486419

\section{Copyrights}

Copyright for this article is retained by the author, with first publication rights granted to the journal.

This is an open-access article distributed under the terms and conditions of the Creative Commons Attribution license (http://creativecommons.org/licenses/by/4.0/). 